\title{
$\boldsymbol{\beta}$-环糊精修饰的壳聚糖对氯酚吸附的动力学和热力学
}

\author{
周良春 ${ }^{1} \quad$ 孟祥光 ${ }^{1, *} \quad$ 李建梅 $^{1}$ 胡 伟 ${ }^{2}$ 刘 波 ${ }^{1}$ 杜 娟 ${ }^{1}$ \\ ('四川大学化学学院, 成都 610064; ${ }^{2}$ 四川理工学院化学与制药工程学院, 四川自贡 643000)
}

\begin{abstract}
摘要: 制备了 $\beta$-环糊精 $(\beta-C D)$ 修饰的壳聚糖(CS)- $\beta$-环糊精-6-壳聚糖(CS-CD), 并用傅里叶变换红外 (FT-IR) 光谱仪, 扫描电镜 (SEM), $X$ 射线衍射 (XRD) 仪和比表面分析仪 (BET)进行了表征. 详细研究了其对 2-氯酚 (2-CP)、2,4-二氯酚 (DCP) 和 2,4,6-三氯酚 (TCP) 的吸附行为和机理. 研究表明其吸附较好地满足 Langmuir 和 Freundlich 吸附模型, $\beta$-环糊精的引入能够较大地提高吸附效率, 2-CP、DCP 和 TCP 在 CS-CD 上吸附的最大 吸附量分别为 14.51 、 50.68 和 $74.29 \mathrm{mg} \cdot \mathrm{g}^{-1}$. 动力学研究表明其吸附速率快, 在 $1 \mathrm{~h}$ 内能达到吸附平衡, 并符合 假二级动力学模型. 计算出了热力学参数 $\Delta G^{0} 、 \Delta H^{0}$ 和 $\Delta S^{0}$ 的值, $\Delta G^{0}$ 为负值表明吸附剂对氯酚的吸附是一个自 发的过程. 电解质和溶液 $\mathrm{pH}$ 值对吸附的影响说明在吸附过程中主要是氯酚与吸附剂之间形成了氢键, 并进一 步讨论了可能的吸附机理. 改性吸附剂易重复利用, 重复使用六次后的质量和吸附效率与初次相比分别保持在 $90 \%$ 和 $82 \%$ 以上, 然而 CS 的质量有较大的损失, 吸附效率也明显降低.
\end{abstract}

关键词: 壳聚糖; $\beta$-环糊精; 吸附; 氯酚; 热力学; 动力学 中图分类号: 0647

\section{Kinetics and Thermodynamics of Adsorption of Chlorophenols onto $\beta$-Cyclodextrin Modified Chitosan}

\author{
ZHOU Liang-Chun ${ }^{1} \quad$ MENG Xiang-Guang ${ }^{1, *} \quad$ LI Jian-Mei ${ }^{1} \quad$ HU Wei $^{2} \quad$ LIU Bo ${ }^{1} \quad$ DU Juan ${ }^{1}$ \\ ( ${ }^{1}$ College of Chemistry, Sichuan University, Chengdu 610064, P. R. China; ${ }^{2}$ School of Chemistry and Pharmaceutical Engineering, \\ Sichuan University of Science \& Engineering, Zigong 643000, Sichuan Province, P. R. China)
}

\begin{abstract}
Cyclodextrin ( $\beta$-CD) modified chitosan (CS), $\beta$-cyclodextrin-6-chitosan (CS-CD), was prepared and subsequently characterized by Fourier transform-infrared (FT-IR) spectroscopy, scanning electron microscopy (SEM), X-ray diffraction (XRD), and Brunauer-Emmett-Teller (BET) analysis. The CS-CD was used as an adsorbent for the adsorption of 2-chlorophenol (2-CP), 2,4-dichlorophenol (DCP), and 2,4,6-tuichlorophenol (TCP) from aqueous solutions. The Langmuir and Freundlich models were applied to describe the adsorption isotherms of the chlorophenols. The adsorption parameters have also been evaluated. The calculated maximum adsorption capacities for 2-CP, DCP, and TCP on CS-CD were $14.51,50.68$, and $74.29 \mathrm{mg} \cdot \mathrm{g}^{-1}$, respectively, indicating that the introduction of the $\beta$-CD moiety greatly increased the adsorption efficiency. Kinetic studies showed that the adsorptions were fast, in that all of the adsorption equilibria were reached within one hour, and that the adsorption processes followed a pseudosecond-order kinetic model. The thermodynamic parameters $\Delta G^{0}, \Delta H^{\circ}$, and $\Delta S^{0}$ were also calculated. The negative $\Delta G^{0}$ values indicated that all of the adsorption processes were spontaneous. A possible adsorption mechanism has been provided and discussed. The effects of electrolytes and $\mathrm{pH}$ values on adsorption revealed that hydrogen bonding between the chlorophenols and CS-CD dominated the adsorption process, which was further confirmed by FT-IR analysis. The adsorbent could be regenerated
\end{abstract}

Received: March 5, 2012; Revised: April 27, 2012; Published on Web: April 28, 2012.

"Corresponding author. Email: mengxgchem@163.com; Tel: +86-28-85462979.

The project was supported by the National Natural Science Foundation of China (21073126) and Key Project of the Science and Technology Department of Zigong, Sichuan Province, China (10X01).

国家自然科学基金(21073126)和四川省自贡市科学技术局重点基金(10X01)资助项目

(C) Editorial office of Acta Physico-Chimica Sinica 
by washing with ethanol. Following six cycles of usage and regeneration, the mass and adsorption efficiency of the CS-CD remained at $90 \%$ and $82 \%$, respectively. CS, however, showed greater mass loss and efficiency reduction following regeneration.

\section{Key Words: Chitosan; $\beta$-Cyclodextrin; Adsorption; Chlorophenols; Thermodynamics; Kinetics}

\section{Introduction}

Chlorophenols are widely existed in various industrial wastewater such as the influents of manufactures of plastics, dyes, drugs, and pesticides. ${ }^{1}$ Chlorophenols could extremely damage the human nervous and respiratory systems. ${ }^{2}$ The removal of chlorophenols from wastewater is of great importance because of their high toxicity, carcinogenicity, and resistance to biodegradation. ${ }^{3}$ The various methods removing chlorophenols from aqueous solution have been widely studied, including biological, chemical, and physical treatments. ${ }^{4}$ Among those methods, adsorption technology is regarded as an efficient technology to remove organic pollutants duo to the convenient operation and low cost. Some adsorbents, such as activated carbon and modified clays, exhibited good adsorption ability for many organic pollutants. ${ }^{5-7}$ However, their regeneration was difficult, which is not suitable to the industry applications. ${ }^{8}$

Chitosan is a kind of polysaccharide prepared from natural chitin. Owing to its non-toxicity, biodegradability, low cost, and biocompatibility, chitosan has been used as a raw material in medical applications such as an immunosuppressant, surgical sures and as a matrix for drug delivery systems. ${ }^{9,10}$ It was also regarded as a green adsorbent to remove organic and inorganic pollutants. ${ }^{11-14}$ However the solubility in acidic aqueous solution and the low capacities of the adsorption of organic compounds limited its further application. Thus some chemical modified chitosan was prepared by introducing some functional groups into the chitosan. ${ }^{15-20}$ Cyclodextrin (CD) was a good candidate owing to its special chemical structure and property. However due to the excellent water-solubility, CD can not be used as adsorbent alone. Thus the $\mathrm{CD}$ grafted on insoluble polymer was suggested. ${ }^{21}$

In previous studies, ${ }^{22}$ we found that $\beta$-CD modified chitosan (CS) exhibited specific adsorption ability for $p$-chlorophenol. In order to investigate other chlorophenols and homologue adsorption on the CS-CD, in this paper we investigated the adsorption processes of 2-CP, DCP, and TCP on modified chitosan. The adsorption interaction mechanism between chlorophenols and CS-CD was also studied.

\section{Materials and methods \\ 2.1 Materials}

Chitosan powder (molecular weight 10000-30000 and 85\% deacetylation degree) purchased from Kelong Chemical Plant (China), was treated through a 200-mesh sieve. $p$-Toluenesulfonyl chloride ( $p$-TsCl, A.R.) was obtained from Ruijinte Chemicals Co., Ltd. (China). $\beta$-cyclodextrin ( $\beta$-CD, C.P.) obtained from Tokyo Kasei Kogyo (Tokyo, Japan) was recrystallized from water and dried in vacuo at $383 \mathrm{~K}$ for $5 \mathrm{~h}$. 2-CP, DCP, TCP, and other reagents used were all analytical grade and without further purification. The $\mathrm{pH}$ value of solution was adjusted with $0.1 \mathrm{~mol} \cdot \mathrm{L}^{-1} \mathrm{H}_{2} \mathrm{SO}_{4}$ or $\mathrm{NaOH}$.

\subsection{Preparation and characterization of absorbent CS-CD}

The preparation of $\beta$-cyclodextrin-6-chitosan (CS-CD) was based on previous literature. ${ }^{17,23}$ The apparent amount of $\beta$-CD grafted on chitosan $\left(\mathrm{DS}_{\mathrm{CD}}\right)$ was measured based on the methods by Dubois et $a l .^{24}$ as following equation:

$$
\mathrm{DS}_{\mathrm{CD}}=\frac{C \times 50 \times 1000}{180 \times 7 \times m}
$$

where $C$ is the concentration of glucose $\left(\mathrm{mg} \cdot \mathrm{L}^{-1}\right)$, and $m$ is the mass of CS-CD (mg). The DS $_{\mathrm{CD}}$ was evaluated as $20.5 \mu \mathrm{mol}$. $\mathrm{g}^{-1}$.

The CS-CD was analyzed by Fourier transform infrared spectrometer (FT-IR, Nicolet NEXUS 670, USA and range $\left.500-4000 \mathrm{~cm}^{-1}\right)$. The samples for FT-IR measurement were obtained by mixing $1 \%(w / w)$ specimen with $100 \mathrm{mg}$ of $\mathrm{KBr}$ powder and pressed into a sheer slice. Solid morphologies of the chitosan (CS) and modified chitosan (CS-CD) were detected by scanning electron microscope (SEM, JSM-7500F, JEOL, Japan). X-ray diffraction (XRD, TD 3500, Dandong, China) pattern was recorded on a Rigaku D/MAX-YA diffractometer with $\mathrm{Ni}$-filtered $\mathrm{Cu} K_{\alpha}$ radiation as the X-ray source. The XRD pattern was recorded from $5^{\circ}$ to $50^{\circ}$ of $2 \theta$. The Brunauer-EmmettTeller (BET, Rise-1030, Runzhi, China) surface area and pore properties of CS and CS-CD were measured by the $\mathrm{N}_{2}$ adsorption at $77 \mathrm{~K}$. Before the BET surface area measurement, the adsorbents were activated at $373 \mathrm{~K}$ for $24 \mathrm{~h}$.

\subsection{Methods and experiments}

The typical adsorption experiment was carried out by immersing $15 \mathrm{mg}$ adsorbent into $25 \mathrm{~mL}$ aqueous solution containing various initial chlorophenol concentrations (20-100 mg • $\mathrm{L}^{-1}$ ) at $\mathrm{pH} 5$ and stirring at $120 \mathrm{r} \cdot \min ^{-1}$ for $3 \mathrm{~h}$ at a constant temperature of $303 \mathrm{~K}$. The chlorophenol solution was separated from the adsorbent by centrifugation and the concentration was determined by UV-Vis spectrophotometer (UV-5300, Yuanxi, China) at 273, 284, and $291.4 \mathrm{~nm}$ for 2-CP, DCP, and TCP, respectively. The adsorption capacity of chlorophenol was calculated by the following equation:

$$
q_{\mathrm{e}}=\frac{\left(C_{0}-C_{\mathrm{e}}\right) V}{m^{\prime}}
$$

where $q_{\mathrm{e}}$ is the equilibrium adsorption capacity per gram adsorbent $\left(\mathrm{mg} \cdot \mathrm{g}^{-1}\right), C_{0}$ and $C_{\mathrm{e}}$ are the initial and equilibrium concentrations of adsorbate in solution $\left(\mathrm{mg} \cdot \mathrm{L}^{-1}\right)$, respectively; $V$ is 
the volume of the solution (L), and $m^{\prime}$ is the mass of dry adsorbent used $(\mathrm{g})$. Each experiment was carried out in triplicate and the standard deviation of adsorption capacity was less than $5 \%$.

\section{Results and discussion}

\subsection{Characterization of absorbent CS-CD}

The presence of certain functional groups and chemical bond in a molecule can be identified by FT-IR spectra. The IR spectra of $\beta$-CD, CS, and CS-CD were illustrated in Fig.1. From Fig.1, it can be seen that the absorption peak of CS-CD at $1598 \mathrm{~cm}^{-1}(\mathrm{~N}-\mathrm{H}$ stretching vibration) is weaker obviously than that of $\mathrm{CS}$, which indicates that the $\mathrm{H}$ atom on $-\mathrm{NH}_{2}$ group has been replaced partly. The absorption peak of CS-CD at $1029 \mathrm{~cm}^{-1}(\mathrm{C}-\mathrm{O}$ stretching vibration) enhances by comparing with CS. The characteristic absorption peak of the $\alpha$-pyranyl vibration of $\beta$-CD at $942 \mathrm{~cm}^{-1}$ appears in the IR spectra of CS-CD, which indicates the presence of $\beta-\mathrm{CD} .{ }^{17}$

Scanning electron microscopy (SEM) images of CS and CS-CD are shown in Fig.2. It can be seen that the granule of $\mathrm{CS}$ and CS-CD is much of a size. However, the surface morphology of CS-CD is cruder than that of CS.

Fig. 3 shows the X-ray diffraction patterns of CS and CSCD. From Fig.3, it can be seen that the change of peak of CS-CD at $2 \theta=20^{\circ}$ is not obvious, however the peak at $2 \theta=12^{\circ}$ becomes weaker obviously than that of CS, which indicates that in the preparing process the hydrogen bond of main body of CS has not been destroyed, and the CD is grafted in amorphous crystal domain and results in the disappear of the peak of amorphous crystal at $2 \theta=12^{\circ}$.

According to $\mathrm{N}_{2}$ adsorption and desorption isotherms, the specific surface area and pore size parameters of the adsor-

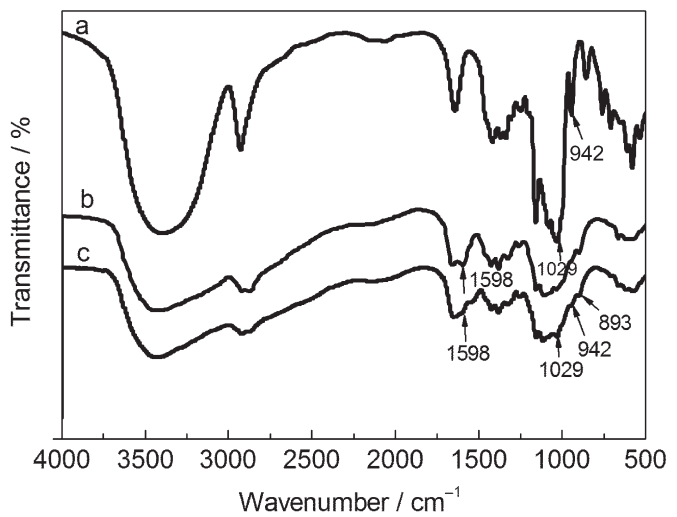

Fig.1 FT-IR spectra of $\beta$-CD (a), CS (b), and CS-CD (c)

bents are listed in Table 1. Form Table 1, it can be seen that both the specific surface area and the pore volume of CS-CD do not change obviously, however the average pore diameter of the CS-CD increases from 1.60 to $3.42 \mathrm{~nm}$ after the introduction of $\beta$-CD.

\subsection{Adsorption isotherms}

Equilibrium adsorption is usually described with an isotherm equation characterized by some parameters which express the surface property and affinity of adsorbent. In this work, adsorptions of 2-CP, DCP, and TCP on two adsorbents (CS and CS-CD) were described with the Langmuir and Freundlich models. Adsorptions of 2-CP and DCP from aqueous solution were carried out at $\mathrm{pH} 5$ and $\mathrm{TCP}$ at $\mathrm{pH} 4$, respectively. Adsorption isotherms of 2-CP, DCP, and TCP onto two adsorbents are shown in Fig.4.

\subsubsection{Langmuir isotherm}

The adsorption processes of many organic compounds have been described successfully by Langmuir adsorption isotherm.
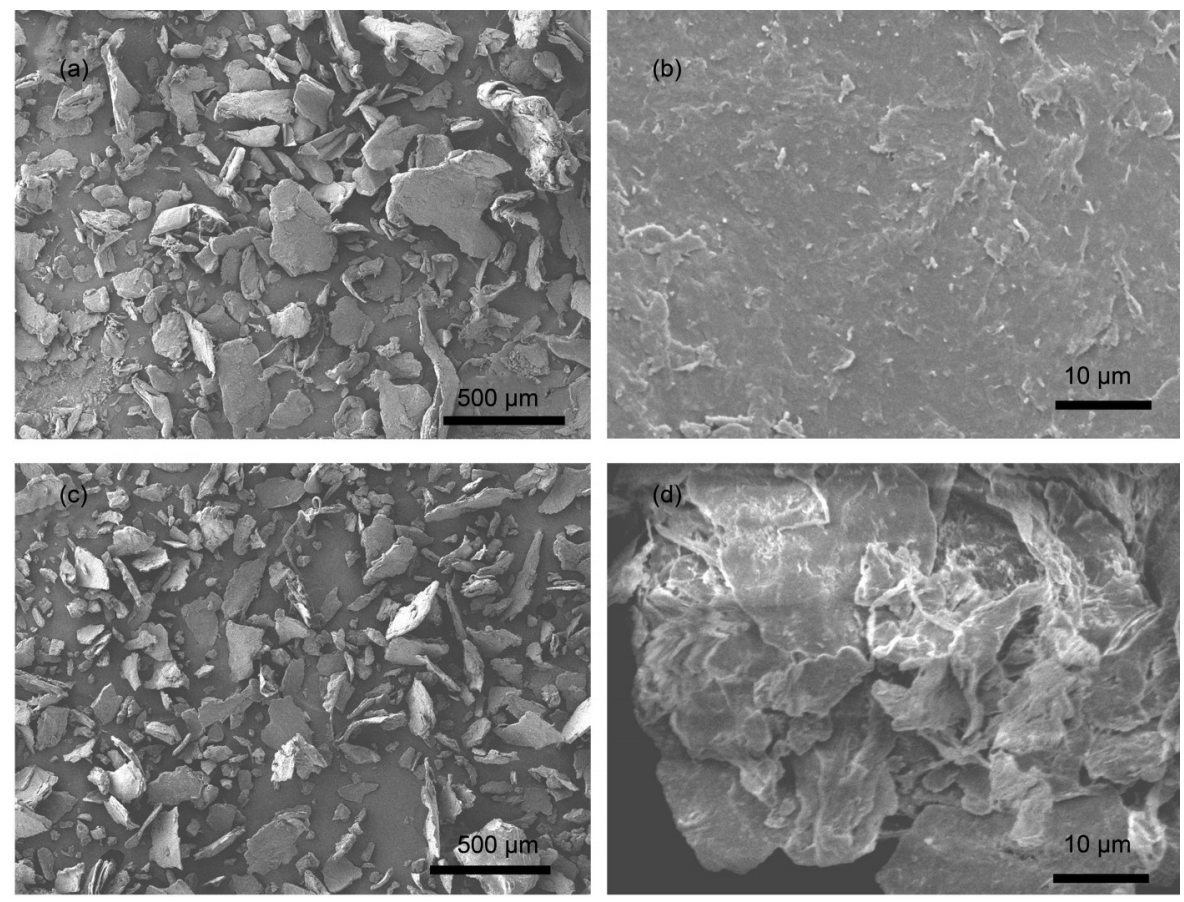

Fig.2 Surface SEM images of CS $(a, b)$ and CS-CD $(c, d)$ at different magnifications 


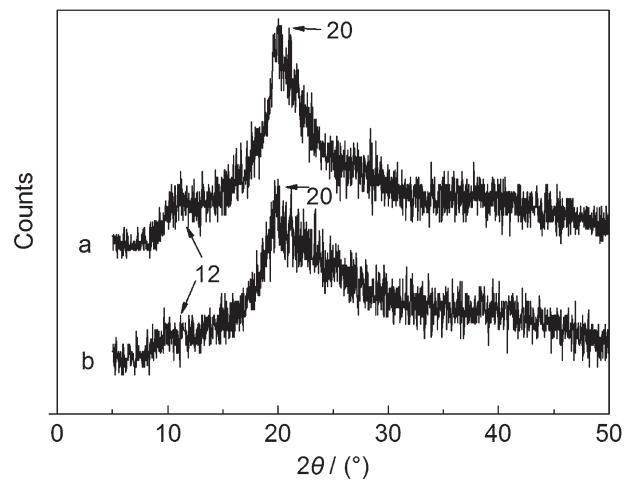

Fig.3 XRD patterns of CS (a) and CS-CD (b)

Table 1 Surface area and pore size parameters of the adsorbents

\begin{tabular}{cccc}
\hline Adsorbent & $S_{\mathrm{BET}} /\left(\mathrm{m}^{2} \cdot \mathrm{g}^{-1}\right)$ & $10^{3} V_{\text {pore }} /\left(\mathrm{cm}^{3} \cdot \mathrm{g}^{-1}\right)$ & $D / \mathrm{nm}$ \\
\hline $\mathrm{CS}$ & 3.27 & 2.00 & 1.60 \\
$\mathrm{CS}-\mathrm{CD}$ & 4.07 & 1.81 & 3.42 \\
\hline$S_{\mathrm{D} T} \cdot$ BET surface area, $V$ & $V_{\text {pre }}$ &
\end{tabular}

Langmuir equation is described as Eq.(3): ${ }^{25}$

$$
q_{\mathrm{e}}=\frac{K_{\mathrm{L}} q_{\mathrm{m}} C_{\mathrm{e}}}{1+K_{\mathrm{L}} C_{\mathrm{e}}}
$$

The rearrangement of Eq.(3) leads to Eq.(4):

$$
\frac{C_{\mathrm{e}}}{q_{\mathrm{e}}}=\frac{1}{K_{\mathrm{L}} q_{\mathrm{m}}}+\frac{C_{\mathrm{e}}}{q_{\mathrm{m}}}
$$

where $K_{\mathrm{L}}$ is the Langmuir isotherm constant related to the energy or net enthalpy, $q_{\mathrm{m}}$ is the maximum adsorption capacity $\left(\mathrm{mg} \cdot \mathrm{g}^{-1}\right)$. According to Eq. (4), the plot of $C_{\mathrm{e}} / q_{\mathrm{e}}$ versus $C_{\mathrm{e}}$ gives a straight line $(r>0.978)$, and values of $K_{\mathrm{L}}$ and $q_{\mathrm{m}}$ can be evaluated from the intercept and slope. Experimental results showed that the linear plots were obtained from $C_{\mathrm{e}} / q_{\mathrm{e}}$ versus $C_{\mathrm{e}}$. The calculated Langmuir parameters are listed in Table 2. Form Table 2, it can be seen that the values of $K_{\mathrm{L}}$ decrease with the increasing $\mathrm{Cl}$ atom when the adsorbent is $\mathrm{CS}-\mathrm{CD}$, which is in accordance with the following thermodynamic data $\left(\Delta H^{0}\right)$.

\subsubsection{Freundlich isotherm}

Another important adsorption isotherm model is the Freundlich adsorption isotherm as described by following equation:

$$
q_{\mathrm{e}}=K_{\mathrm{F}} C_{\mathrm{e}}^{1 / n}
$$

where $K_{\mathrm{F}}\left(\mathrm{mg}^{1-1 / n} \cdot \mathrm{L}^{1 / n} \cdot \mathrm{g}^{-1}\right)$ and $n$ are Freundlich constants related to the adsorption capacity and adsorption intensity of the adsorbent, respectively. A value for $1 / n$ below one indicates a normal Langmuir isotherm while $1 / n$ above one is indicative for a cooperative adsorption. ${ }^{26}$

$$
\text { Eq.(5) can be rearranged into Eq.(6): }
$$

$$
\ln q_{\mathrm{e}}=\ln K_{\mathrm{F}}+\frac{1}{n} \ln C_{\mathrm{e}}
$$

The plot of $\ln q_{\mathrm{e}}$ versus $\ln C_{\mathrm{e}}$ gives a straight line $(r>0.991)$, and values of $K_{\mathrm{F}}$ and $1 / n$ can be evaluated from the intercept and slope, respectively. The obtained values of $1 / n$ and $K_{\mathrm{F}}$ are listed in Table 2. From Table 2, it can be observed that values of $1 / n$ range from 0 to 1 under studied conditions, which indicate that the adsorption processes for chlorophenol on two adsorbents are favorable. ${ }^{27}$ For the same adsorbent, the values of $K_{\mathrm{F}}$ in-
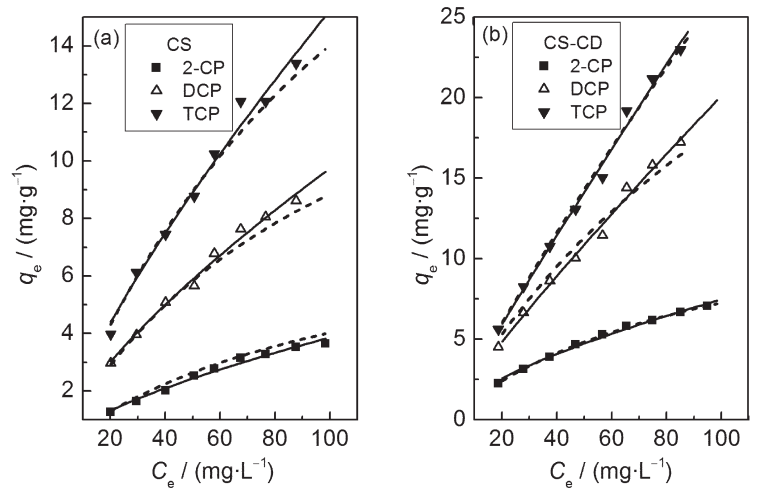

Fig.4 Adsorption isotherms of chlorophenols onto CS (a) and CS-CD (b)

$q_{\mathrm{e}}$ is the equilibrium adsorption capacity, $C_{\mathrm{e}}$ is the equilibrium concentration of adsorbate. dotted line: theoretical curve of Langmuir equation, solid line: theoretical curve of Freundlich equation

creased with the increasing $\mathrm{Cl}$ atom, which was in accordance with the change of the $q_{\mathrm{m}}$ values. Experimental results showed that all linear correlation coefficient $r$ values were good ( $r>$ 0.978 ) and all the standard deviation were enough small (the standard deviation $<5 \%$ ), which indicated that the experimental data of this work obeyed the adsorption models of Langmuir and Freundlich.

\subsubsection{Adsorption efficiency}

From Table 2, it can be found that the modified chitosan CS-CD exhibits better adsorption efficiency than pure chitosan, which suggests that the introduction of $\beta$-CD functional group increases the adsorption efficiency. It can be also found that the adsorption capacities of three chlorophenols on CS or $\mathrm{CS}-\mathrm{CD}$ increase with increasing the number of $\mathrm{Cl}$ atom. Chlorophenols can form hydrogen bond with CS-CD. In detail, the $-\mathrm{OH}$ and $-\mathrm{Cl}$ in chlorophenols can form hydrogen bond with not only $-\mathrm{OH}$ and/or $-\mathrm{NH}_{2}$ in $\mathrm{CS}$ but also $-\mathrm{OH}$ in $\beta$-CD. The more chlorine atoms, the more hydrogen bonds could be formed. Thus the adsorption efficiency and intensity on either CS or CS-CD increase with increasing the number of chlorine atoms. CS-CD contains more hydroxyl groups due to

\begin{tabular}{|c|c|c|c|c|c|c|}
\hline & \multicolumn{3}{|c|}{ Langmuir adsorption isotherm } & \multicolumn{3}{|c|}{ Freundlich adsorption isotherm } \\
\hline & $q_{\mathrm{m}} /\left(\mathrm{mg} \cdot \mathrm{g}^{-1}\right)$ & $10^{3} K_{\mathrm{L}} /\left(\mathrm{L} \cdot \mathrm{mg}^{-1}\right)$ & $r$ & $1 / n$ & $K_{\mathrm{F}} /\left(\mathrm{mg}^{1-1 / n} \cdot \mathrm{L}^{1 / n} \cdot \mathrm{g}^{-1}\right)$ & $r$ \\
\hline \multicolumn{7}{|c|}{$\mathrm{CS}$} \\
\hline $2-\mathrm{CP}$ & 8.37 & 9.06 & 0.985 & 0.70 & 0.154 & 0.995 \\
\hline DCP & 15.39 & 12.90 & 0.996 & 0.63 & 0.489 & 0.995 \\
\hline TCP & 29.65 & 9.38 & 0.978 & 0.73 & 0.532 & 0.991 \\
\hline \multicolumn{7}{|c|}{ CS-CD } \\
\hline 2-CP & 14.51 & 9.80 & 0.998 & 0.70 & 0.307 & 0.997 \\
\hline DCP & 50.68 & 5.46 & 0.995 & 0.80 & 0.464 & 0.999 \\
\hline TCP & 74.29 & 5.13 & 0.997 & 0.83 & 0.593 & 0.999 \\
\hline
\end{tabular}
the existence of $\beta$-CD. Therefore the adsorption capacity of chlorophenols on CS-CD is larger than that on CS. Additional-

Table 2 Evaluated Langmuir and Freundlich parameters for the adsorption of chlorophenols onto adsorbents at $303 \mathrm{~K}$

$q_{\mathrm{m}}$ is the maximum adsorption capacity, $K_{\mathrm{L}}$ is the constant related to the energy, $r$ is linear correlation coefficient, $n$ is the constant on adsorption intensity, and $K_{\mathrm{F}}$ is the constant on the adsorption capacity. 
ly, the $\beta$-CD with a cavity of diameter of about $0.8 \mathrm{~nm}$ can form host-guest complexes with many organic molecules, especially for those with phenyl groups, fitting partially or completely into the host $\mathrm{CD}$ cavity. ${ }^{28}$ For chlorophenols, it is easy to enter into $\mathrm{CD}$ cavity because of the property of poor water-solubility. However, CD cavity can contain only three chlorophenol molecules owing to the limit of small cavity size. However, according to the experimental data of this work, the quantities of 2-CP, DCP, and TCP on the CD unit are evaluated $2.33,10.56,11.03$ molecules per CD molecule, respectively. Therefore these experimental results indicate that the adsorption of chlorophenols on CS-CD is mainly predominated by hydrogen bond between adsorbate and adsorbent.

\subsection{Adsorption kinetics}

In order to understand the mechanism of adsorption, the adsorption kinetics was studied. The adsorption kinetic curves $\left(q_{t}\right.$ versus $t$ ) of chlorophenols on CS and CS-CD are illustrated in Fig.5. From Fig.5, it can be seen that the adsorption of chlorophenols onto chitosan based adsorbent is rapid and all adsorption equilibrium can be reached within $1 \mathrm{~h}$. In this work, the samples were left for $3 \mathrm{~h}$ to ensure the sorption equilibrium.

A linear form of pseudo-first-order model is described as Eq. $(7):{ }^{29}$

$$
\ln \left(q_{\mathrm{e}}-q_{t}\right)=\ln q_{\mathrm{e}}-k_{1} t
$$

where $q_{t}$ and $q_{\mathrm{e}}$ refer to the amount of chlorophenol adsorbed $\left(\mathrm{mg} \cdot \mathrm{g}^{-1}\right)$ at time $t(\mathrm{~min})$ and equilibrium, respectively. $k_{1}$ is the equilibrium rate constant $\left(\mathrm{min}^{-1}\right)$ of pseudo-first-order sorption. The values of $q_{\mathrm{e}}$ and $k_{1}$ can be evaluated from Eq.(7). The pseudo-first-order rate constants are calculated and listed in Table 3.

The adsorption kinetic model of pseudo-second-order was described as Eq.(8): ${ }^{30}$

$$
\frac{t}{q_{t}}=\frac{1}{k_{2} q_{\mathrm{e}}^{2}}+\frac{t}{q_{\mathrm{e}}}
$$

where $k_{2}$ is the rate constant $\left(\mathrm{g} \cdot \mathrm{mg}^{-1} \cdot \mathrm{min}^{-1}\right)$ of pseudo-secondorder sorption. The plot of $t / q_{t}$ versus $t$ gives a straight line (Fig.5) and the values of $q_{\mathrm{e}}$ and $k_{2}$ can be evaluated from the slope and intercept. The calculated results are listed in Table 3.

From Table 3, it can be seen that the values of $q_{\mathrm{e}}(\mathrm{cal})$ calculated based on Eq.(7) are great different from those of $q_{\mathrm{e}}(\exp )$ obtained from experiments. The correlation coefficients $(r)$ are
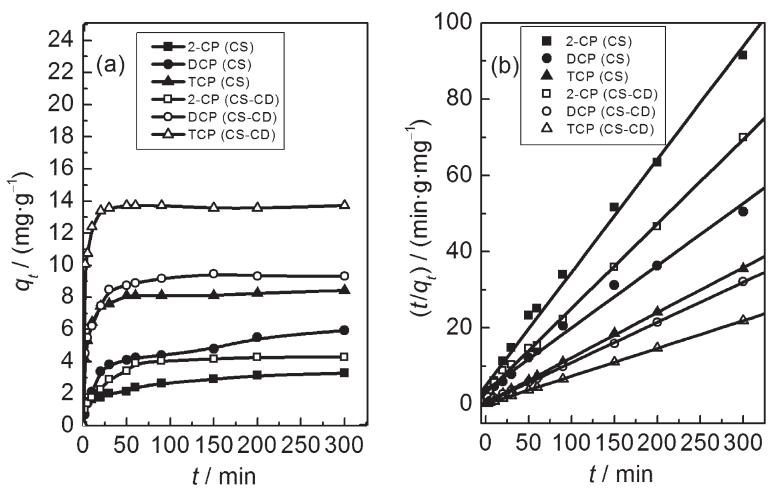

Fig.5 Plots of adsorption capacities of chlorophenols onto CS and CS-CD versus time $t(\mathrm{a})$, and the linear plots of $t / q_{t}$ versus $t$ (b) $q_{t}$ is the amount of chlorophenol adsorbed at time $t$, $C_{0}$ (chlorophenols) $=50 \mathrm{mg} \cdot \mathrm{L}^{-1}, T=303 \mathrm{~K}$

also poor. These results indicate that the adsorption processes do not obey pseudo-first-order kinetics model. From Table 3, it can be also found that the values of $q_{\mathrm{e}}(\mathrm{cal})$ calculated based on Eq.(8) are in good agreement with those $q_{\mathrm{e}}(\exp )$ obtained from experiment. And the correlation coefficients are also more than 0.995 . This indicates that the adsorptions of chlorophenols onto CS-CD obey pseudo-second-order kinetics model. Further the result displays that the adsorption process is a chemical adsorption, which is in accordance with the following thermodynamic data. From Table 3, we also find that for DCP and TCP the adsorption kinetic rate constant $\left(k_{2}\right)$ values are much larger on CS-CD than those on CS, for 2-CP the $k_{2}$ values keep almost unchanged because of the weaker hydrogen bond interaction between 2-CP and CS or CS-CD. These results clearly indicate that the introduction of $\mathrm{CD}$ increases not only the adsorption capacity and intensity (Table 2 ) but also the adsorption rate of chlorophenol.

\subsection{Adsorption thermodynamics}

To further study the adsorption process, the effect of temperature on the adsorption capacity was studied by carrying out the experiment at $303,313,323$, and $333 \mathrm{~K}$. The adsorption would be described by the thermodynamic parameters such as the adsorption equilibrium constant $\left(K_{0}\right)$, Gibbs free energy change $\left(\Delta G^{0}\right)$, enthalpy change $\left(\Delta H^{0}\right)$, and entropy change $\left(\Delta S^{0}\right)$.

The distribution adsorption coefficient $K_{\mathrm{d}}\left(\mathrm{mL} \cdot \mathrm{g}^{-1}\right)$ can be

\begin{tabular}{|c|c|c|c|c|c|c|c|}
\hline & \multirow{2}{*}{$q_{\mathrm{e}}(\mathrm{exp}) /\left(\mathrm{mg} \cdot \mathrm{g}^{-1}\right)$} & \multicolumn{2}{|c|}{ Pseudo-first-order } & \multirow[b]{2}{*}{$r$} & \multicolumn{3}{|c|}{ Pseudo-second-order } \\
\hline & & $q_{\mathrm{e}}(\mathrm{cal}) /\left(\mathrm{mg} \cdot \mathrm{g}^{-1}\right)$ & $k_{1} / \mathrm{min}^{-1}$ & & $q_{\mathrm{e}}(\mathrm{cal}) /\left(\mathrm{mg} \cdot \mathrm{g}^{-1}\right)$ & $k_{2} /\left(\mathrm{g} \cdot \mathrm{mg}^{-1} \cdot \mathrm{min}^{-1}\right)$ & $r$ \\
\hline \multicolumn{8}{|c|}{$\mathrm{CS}$} \\
\hline 2-CP & 3.38 & 1.94 & 0.0127 & 0.990 & 3.37 & 0.0179 & 0.999 \\
\hline DCP & 5.93 & 3.85 & 0.0105 & 0.948 & 6.10 & 0.0075 & 0.995 \\
\hline $\mathrm{TCP}$ & 8.43 & 2.08 & 0.0127 & 0.813 & 8.46 & 0.0235 & 0.999 \\
\hline \multicolumn{8}{|c|}{ CS-CD } \\
\hline 2-CP & 4.29 & 2.87 & 0.0135 & 0.967 & 4.51 & 0.0169 & 0.999 \\
\hline DCP & 9.32 & 4.27 & 0.0394 & 0.987 & 9.49 & 0.0287 & 0.999 \\
\hline TCP & 13.72 & 4.55 & 0.1170 & 0.990 & 13.74 & 0.1120 & 0.999 \\
\hline
\end{tabular}

Table 3 Kinetic parameters of chlorophenols adsorption on CS and CS-CD at $303 \mathrm{~K}$ 


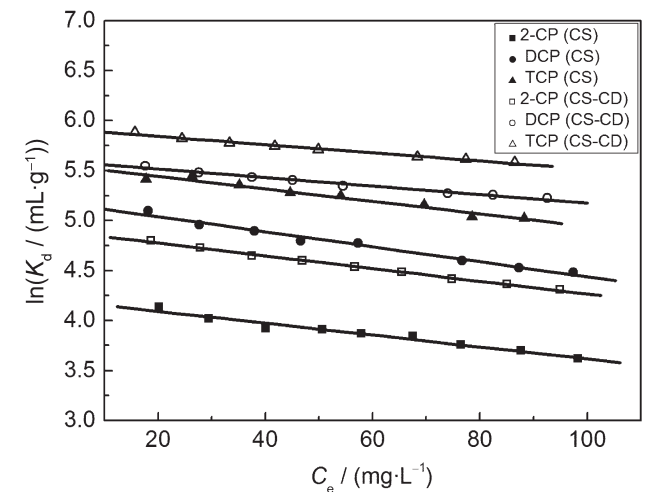

Fig.6 Linear plots of $\ln K_{\mathrm{d}}$ versus $C_{\mathrm{e}}$ for the adsorption of chlorophenols on CS and CS-CD at $303 \mathrm{~K}$

$K_{\mathrm{d}}$ is the distribution adsorption coefficient.

calculated as Eq.(9): $:^{31}$

$$
K_{\mathrm{d}}=\frac{q_{\mathrm{e}}}{C_{\mathrm{e}}} \times 1000
$$

$K_{0}$ can be obtained by plotting $\ln K_{\mathrm{d}}$ versus $C_{\mathrm{e}}$ and extrapolating $C_{\mathrm{e}}$ to zero in the low adsorbate solution concentration range. ${ }^{32}$ The value of the intercept is the value of $\ln K_{0}$. The linear plots of $\ln K_{\mathrm{d}}$ versus $C_{\mathrm{e}}$ are illustrated in Fig.6. Similarly, the values of $\ln K_{0}$ at 313,323 , and $333 \mathrm{~K}$ are calculated and listed in Table 4.

Gibbs free energy change $\left(\Delta G^{0}\right)$ was calculated according to the following equation: ${ }^{32}$

$$
\Delta G^{0}=-R T \ln K_{0}
$$

where $R$ is the universal gas constant, $8.314 \mathrm{~J} \cdot \mathrm{mol}^{-1} \cdot \mathrm{K}^{-1}, T$ is the Kelvin temperature $(\mathrm{K})$.

Thermodynamic parameters $\left(\Delta G^{0}, \Delta H^{0}\right.$, and $\left.\Delta S^{0}\right)$ can be evaluated from Eqs.(11) and (12): ${ }^{33}$

$$
\begin{aligned}
& \Delta G^{0}=\Delta H^{0}-T \Delta S^{0} \\
& \ln K_{0}=\frac{\Delta S^{0}}{R}-\frac{\Delta H^{0}}{R T}
\end{aligned}
$$

Thus $\Delta H^{0}$ and $\Delta S^{0}$ were obtained from the slope and intercept of the line plotted by $\ln K_{0}$ versus $1 / T$. The obtained thermodynamic parameters are listed in Table 4.

From Table 4, it can be seen that the values of $\Delta G^{0}$ and $\Delta H^{0}$ are in the range of -10.61 to $-16.53 \mathrm{~kJ} \cdot \mathrm{mol}^{-1}$ and -13.14 to $48.75 \mathrm{~kJ} \cdot \mathrm{mol}^{-1}$, respectively. These results indicate that the adsorption process of chlorophenol is a chemical adsorption. ${ }^{34}$ The negative $\Delta G^{0}$ values indicate that all these adsorption pro-

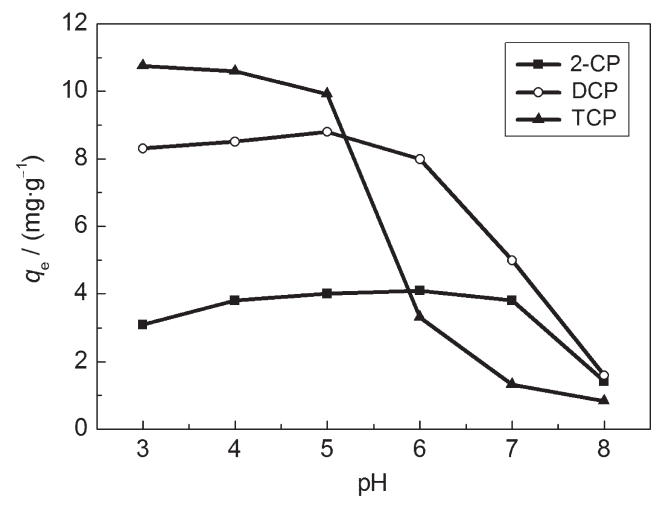

Fig.7 Effects of $\mathrm{pH}$ value on the adsorptions of chlorophenols onto CS-CD

$C_{0}($ chlorophenols $)=40 \mathrm{mg} \cdot \mathrm{L}^{-1}$, contact time: $3 \mathrm{~h}, T=303 \mathrm{~K}$

cesses are spontaneous. ${ }^{35}$ Due to the existence of $\beta$-CD, chlorophenol can form more hydrogen bonds on modified chitosan and thus result in much less $\Delta H^{0}$ than chitosan. Due to the interaction of hydrogen bond, the more numbers of $\mathrm{Cl}$ atoms, the more quantities of hydrogen bonds, the smaller $\Delta H^{0}$. Form Table 4 , it can be observed that the values of $\Delta H^{0}$ are more than $T \Delta S^{0}$ when the adsorbate is TCP, which indicates that the adsorption process has been driven by enthalpy $\Delta H^{0}$ rather than $\Delta S^{0}$. From Table 4 , we find that the $\Delta S^{0}$ values are all positive and decrease with increasing the number of $\mathrm{Cl}$ atoms. This detailed mechanism is still unclear. It is possible that two factors lead to this positive $\Delta S^{0}$ : the adsorption of chlorophenols onto adsorbent would cause the split of hydrogen bond of macromolecule chitosan, which results in the entropy increase; the other factor is the effect of the associated $\mathrm{H}_{2} \mathrm{O}$. In the adsorption process, some associated $\mathrm{H}_{2} \mathrm{O}$ molecules with adsorbent were possibly replaced by chlorophenol, which also leaded to the entropy increase of system. The more quantities of hydrogen bond would increase with increasing the number of $\mathrm{Cl}$ atoms, which would result in the decrease of entropy.

\subsection{Effect of $\mathrm{pH}$}

Adsorptions of 2-CP, DCP, and TCP onto CS-CD are carried out in the $\mathrm{pH}$ range of $3.0-8.0$ at $303 \mathrm{~K}$ for $3 \mathrm{~h}$. The effects of $\mathrm{pH}$ value on the adsorptions are illustrated in Fig.7.

It can be seen that the $\mathrm{pH}$ value of solution has hardly influ-

\begin{tabular}{|c|c|c|c|c|c|c|c|c|c|c|}
\hline & \multicolumn{4}{|c|}{$\ln K_{0}$} & \multicolumn{4}{|c|}{$\Delta G^{0} /\left(\mathrm{kJ} \cdot \mathrm{mol}^{-1}\right)$} & \multirow{2}{*}{$\Delta H^{0} /\left(\mathrm{kJ} \cdot \mathrm{mol}^{-1}\right)$} & \multirow{2}{*}{$\Delta S^{0} /\left(\mathrm{J} \cdot \mathrm{mol}^{-1} \cdot \mathrm{K}^{-1}\right)$} \\
\hline & $303 \mathrm{~K}$ & $313 \mathrm{~K}$ & $323 \mathrm{~K}$ & $333 \mathrm{~K}$ & $303 \mathrm{~K}$ & $313 \mathrm{~K}$ & $323 \mathrm{~K}$ & $333 \mathrm{~K}$ & & \\
\hline \multicolumn{11}{|c|}{$\mathrm{CS}$} \\
\hline 2-CP & 4.21 & 4.81 & 5.34 & 5.97 & -10.61 & -12.52 & -14.34 & -16.53 & 48.75 & 195.73 \\
\hline DCP & 5.19 & 5.40 & 5.61 & 5.80 & -13.07 & -14.05 & -15.07 & -16.06 & 17.13 & 99.66 \\
\hline TCP & 5.57 & 5.45 & 5.35 & 5.24 & -14.03 & -14.18 & -14.37 & -14.51 & -9.15 & 16.10 \\
\hline \multicolumn{11}{|c|}{ CS-CD } \\
\hline 2-CP & 4.90 & 5.03 & 5.26 & 5.47 & -12.34 & -13.09 & -14.13 & -15.14 & 16.24 & 94.07 \\
\hline DCP & 5.60 & 5.69 & 5.76 & 5.81 & -14.11 & -14.81 & -15.47 & -16.09 & 5.90 & 66.08 \\
\hline $\mathrm{TCP}$ & 5.92 & 5.69 & 5.57 & 5.44 & -14.91 & -14.81 & -14.96 & -15.06 & -13.14 & 5.63 \\
\hline
\end{tabular}
ence on the adsorption capacity in the $\mathrm{pH}$ range of 3-5, however the turning points of adsorption of 2-CP, DCP, and TCP onto

Table 4 Thermodynamic parameters for the adsorption of chlorophenols onto CS and CS-CD

$K_{0}$ is the adsorption equilibrium constant, $\Delta G^{0}$ is Gibbs free energy change, $\Delta H^{0}$ is enthalpy change, and $\Delta S^{0}$ is entropy change. 
CS-CD are $\mathrm{pH} 7, \mathrm{pH} 6$, and $\mathrm{pH}$, respectively. Since the $\mathrm{p} K_{\mathrm{a}}$ values of 2-CP, DCP, and TCP are 8.3, 7.7, and 6.1, respectively. ${ }^{36}$ When the $\mathrm{pH}$ values of solution are below $\mathrm{p} K_{\mathrm{a}}$ of chlorophenol, they mainly exist as molecules. On the contrary, chlorophenol mainly exists as negative chlorophenolate ions. Fig.7 shows that the adsorption capacities are larger when chlorophenol mainly exists as molecules. Therefore, it can be concluded that chlorophenol adsorbed onto CS-CD is mainly in the form of molecule state rather than that of chlorophenolate anion.

\subsection{Effect of salt}

In order to investigate the effect of electrostatic interaction, $\mathrm{Na}_{2} \mathrm{SO}_{4}$ or $\mathrm{LiCl}$ was added into the chlorophenol solution. The equilibrium adsorption capacities of 2-CP, DCP, and TCP onto CS-CD were investigated. Adsorption experiments of 2-CP and DCP were carried out at $\mathrm{pH} 5$ and TCP at $\mathrm{pH} 4$. Salt concentration was adjusted in the range from 0 to $1.0 \mathrm{~mol} \cdot \mathrm{L}^{-1}$ and the experimental results are illustrated in Fig.8. From Fig.8, it can be found that the addition of $\mathrm{LiCl}$ leads to the decrease of the adsorption capacities of chlorophenols in the beginning. A possible reason is that as a Brönsted acid the $\mathrm{Li}^{+}$could associate with $\mathrm{O}$ atom of chlorophenols to hinder the formation of hydrogen bond of $\mathrm{O}$ atom of chlorophenols with adsorbent. $\mathrm{Na}^{+}$ causes this effect to be poor. However in the case of high concentration, electrolyte $\mathrm{LiCl}$ and $\mathrm{Na}_{2} \mathrm{SO}_{4}$ could destroy the hydrogen bond network of macromolecule CS-CD and thus chlorophenols can enter the new inter space. Therefore the adsorption capacities of chlorophenols increase with increasing the concentration of additional $\mathrm{Na}_{2} \mathrm{SO}_{4}$ and $\mathrm{LiCl}$.

\subsection{FT-IR spectra}

The IR spectra of the DCP, CS-CD, and CS-CD adsorbing DCP are shown in Fig.9. Form Fig.9, it can be seen that the adsorption peak at $3425 \mathrm{~cm}^{-1}$ of $-\mathrm{OH}$ group in $\mathrm{CS}$ and $\beta$-CD shifts to higher frequency $\left(3444 \mathrm{~cm}^{-1}\right)$. The peak of the $-\mathrm{OH}$ of chlorophenol at $3439 \mathrm{~cm}^{-1}$ also moves. The peak at 1598 $\mathrm{cm}^{-1}$ of $-\mathrm{NH}$ or $-\mathrm{NH}_{2}$ group of CS shifts to lower frequency $\left(1588 \mathrm{~cm}^{-1}\right)$. After CS-CD adsorbs DCP, the peak of the $\mathrm{C}-\mathrm{O}$ stretching vibration moves from 1029 to $1043 \mathrm{~cm}^{-1}$, which indicates that there is a relative strong interaction between DCP

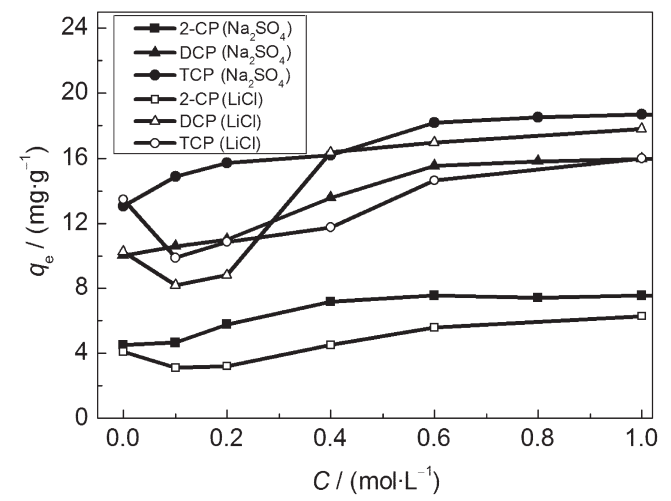

Fig.8 Effect of salt concentration on the adsorptions of 2-CP (pH 5), DCP (pH 5), and TCP (pH 4) onto CS-CD

$C$ is the salt concentration, $C_{0}$ (chlorophenols) $=50 \mathrm{mg} \cdot \mathrm{L}^{-1}$, contact time: $3 \mathrm{~h}, T=303 \mathrm{~K}$

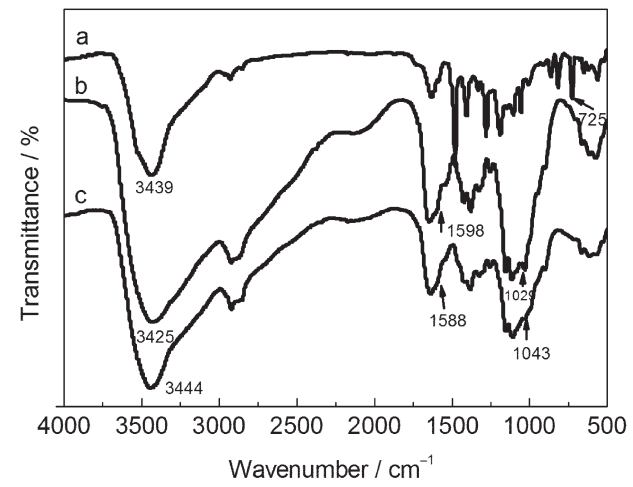

Fig.9 FT-IR spectra of DCP (a), CS-CD (b), and CS-CD adsorbing DCP (c)

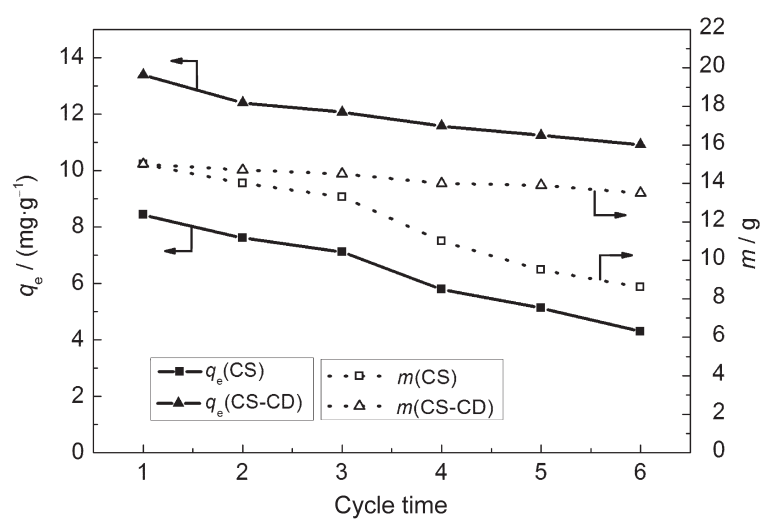

Fig.10 Effects of cycle times on the adsorption efficiencies and the masses of CS and CS-CD

$C_{0}(\mathrm{TCP})=50 \mathrm{mg} \cdot \mathrm{L}^{-1}$, contact time: $3 \mathrm{~h}, \mathrm{pH}=4, T=303 \mathrm{~K}$

and CS-CD. The $\mathrm{C}-\mathrm{Cl}$ stretching vibration at $725 \mathrm{~cm}^{-1}$ also changes obviously. This indicates that there is the interaction between $\mathrm{Cl}$ atoms and the $-\mathrm{NH}$ or $-\mathrm{NH}_{2} /-\mathrm{OH}$. As mentioned above, there is a hydrogen bonding interaction between CS-CD and DCP. Thus IR spectra provide the evidence that the hydrogen bonds are formed between chlorophenol and CS-CD.

\section{Adsorbent regeneration}

In order to study the adsorption efficiency, adsorbate isolation and adsorbent regeneration were investigated. In this work chlorophenol could be easily desorbed from adsorbent by using ethanol. The adsorbent adsorbing chlorophenol was immersed into $20 \mathrm{~mL}$ ethanol and stirred at $313 \mathrm{~K}$ for $3 \mathrm{~h}$. Then the adsorbent was separated by filtering and dried at $383 \mathrm{~K}$ for $2 \mathrm{~h}$. The effects of cycle times on the adsorption of TCP onto CS and CS-CD were illustrated as Fig.10. It can be obviously found that the adsorption efficiency of CS-CD for TCP remains above $82 \%$ after six times' usage while the value of CS decreases to $50 \%$. From Fig. 10, it can also be found that the mass of the CS reduces by $42.7 \%$, while the mass of CS-CD reduces less than $10 \%$ after six times' usage. This indicates that the modified CS-CD has better physico-chemical stability.

\section{Conclusions}


The modified chitosan prepared in this work displays better adsorption ability for 2-CP, DCP, and TCP. The maximum adsorption capacities for 2-CP, DCP, and TCP on CS-CD are $14.51,50.68$, and $74.29 \mathrm{mg} \cdot \mathrm{g}^{-1}$, respectively. Comparing with the CS, the modified chitosan CS-CD can obviously increase the adsorption ability for chlorophenols. The adsorption of chlorophenols onto CS and CS-CD obeys pseudo-second-order kinetics model. Negative $\Delta G^{0}$ reveals that all these adsorption processes are spontaneous. The adsorption is predominated mainly by hydrogen bond interaction between chlorophenols and CS-CD. The adsorption efficiency of the modified chitosan remains $82 \%$ and mass reduces less than $10 \%$ after six times' usage. Contrarily CS shows great mass loss (42.7\%) and efficiency reduction (50\%) after regeneration.

\section{References}

(1) Moradi, M.; Yamini, Y.; Esrafili, A.; Seidi, S. Talanta 2010, 82, 1864. doi: 10.1016/j.talanta.2010.08.002

(2) Hamad, B. K.; Noor, A. M.; Afida, A. R.; Asri, M. N. M. Desalination 2010, 257, 1. doi: 10.1016/j.desal.2010.03.007

(3) Tsutsui, T.; Hayashi, N.; Maizumi, H.; Huff, J.; Barrett, J. C. Mutat. Res-Fund. Mol. M. 1997, 373, 113. doi: 10.1016/S00275107(96)00196-0

(4) Dominguez-Vargas, J. R.; Navarro-Rodriguez, J. A.; de Herediaa, J. B.; Cuerda-Correa, E. M. J. Hazard. Mater. 2009, 169, 302. doi: 10.1016/j.jhazmat.2009.03.075

(5) Sampa, M. H. D. O.; Rela, P. R.; Las Casas, A.; Mori, M. N.; Duarte, C. L. Radiat. Phys. Chem. 2004, 71, 459. doi: 10.1016/ j.radphyschem.2004.03.023

(6) Jain, S.; Jayaram, R. V. Sep. Sci. Technol. 2007, 42, 2019. doi: 10.1080/15275920701313608

(7) Hu, Q. H.; Qiao, S. Z.; Haghseresht, F.; Wilson, M. A.; Lu, G. Q. Ind. Eng. Chem. Res. 2006, 45, 733. doi: 10.1021/ie050889y

(8) Maugans, C. B.; Akgerman, A. Water Res. 2003, 37, 319. doi: 10.1016/S0043-1354(02)00289-0

(9) Chiou, S. H.; Wu, W. T.; Huang, Y. Y.; Chung, T. W. J. Microencapsul. 2001, 18, 613. doi: 10.1080/ 02652040010019497

(10) Chiu, S. H.; Chung, T. W.; Giridhar, R.; Wu, W. T. Food Res. Int. 2004, 37, 217. doi: 10.1016/j.foodres.2003.12.001

(11) Milhome, M. A. L.; de Keukeleire, D.; Ribeiro, J. P.; Nascimento, R. F.; Carvalho, T. V.; Queiroz, D. C. Quim. Nova 2009, 32, 2122. doi: 10.1590/S0100-40422009000800025

(12) Crini, G.; Badot, P. M. Prog. Polym. Sci. 2008, 33, 399. doi: 10.1016/j.progpolymsci.2007.11.001

(13) Dotto, G. L., Pinto, L. A. A. J. Hazard. Mater. 2011, 187, 164. doi: 10.1016/j.jhazmat.2011.01.016

(14) Guibal, E. Sep. Purif. Technol. 2004, 38, 43. doi: 10.1016/ j.seppur.2003.10.004

(15) Zhou, L. M.; Shang, C.; Liu, Z. R. Acta Phys. -Chim. Sin. 2011,
27, 677. [周利民, 尚 超, 刘峙嵘. 物理化学学报, 2011, 27, 677.] doi: 10.3866/PKU.WHXB20110314

(16) Zheng, J. N.; Xie, H. G.; Yu, W. T.; Liu, X. D.; Xie, W. Y.; Zhu, J.; Ma, X. J. Langmuir 2010, 26, 17156. doi: 10.1021/ la1030203

(17) Zhang, X. Y.; Wang, Y. T.; Yi, Y. J. Appl. Polym. Sci. 2004, 94 , 860. doi: 10.1002/app.20759

(18) Prabaharan, M.; Mano, J. F. Carbohyd. Polym. 2006, 63, 153. doi: 10.1016/j.carbpol.2005.08.051

(19) Sharma, A. K.; Mishra, A. K. Int. J. Biol. Macromol. 2010, 47, 410. doi: 10.1016/j.ijbiomac.2010.06.012

(20) Hall, L. D.; Yalpani, M. Carbohyd. Res. 1980, 83, C5.

(21) Ozmen, E. Y.; Sezgin, M.; Yilmaz, A.; Yilmaz, M. Bioresource Technol. 2008, 99, 526. doi: 10.1016/j.biortech.2007.01.023

(22) Li, J. M.; Meng, X. G.; Hu, C. W.; Du, J. Bioresource Technol. 2009, 100, 1168. doi: 10.1016/j.biortech.2008.09.015

(23) Wang, H.; Fang, Y.; Ding, L. P.; Gao, L. N.; Hu, D. D. Thin Solid Films 2003, 440, 255. doi: 10.1016/S0040-6090(03) 00812-5

(24) Dubois, M.; Gilles, K. A.; Hamilton, J. K.; Rebers, P. A.; Smith, F. Anal. Chem. 1956, 28, 350. doi: 10.1021/ac60111a017

(25) Ghiaci, M.; Abbaspur, A.; Kia, R.; Seyedeyn-Azad, F. Sep. Purif. Technol. 2004, 40, 217. doi: 10.1016/j.seppur.2004.03. 001

(26) Ma, J. W.; Wang, H.; Wang, F. Y.; Huang, Z. H. Sep. Sci. Technol. 2010, 45, 2329. doi: 10.1080/01496395.2010.504482

(27) Wu, X. B.; Wu, D. C.; Fu, R. W. J. Hazard. Mater. 2007, 147, 1028. doi: 10.1016/j.jhazmat.2007.01.139

(28) Chen, C. Y.; Chen, C. C.; Chung, Y. C. Bioresource Technol. 2007, 98, 2578. doi: 10.1016/j.biortech.2006.09.009

(29) Alkaram, U. F.; Mukhlis, A. A.; Al-Dujaili, A. H. J. Hazard. Mater. 2009, 169, 324. doi: 10.1016/j.jhazmat.2009.03.153

(30) Ho, Y. S.; McKay, G. Water Res. 2000, 34, 735. doi: 10.1016/ S0043-1354(99)00232-8

(31) Feng, Y. J.; Zhang, Z. H.; Gao, P.; Su, H.; Yu, Y. L.; Ren, N. Q. J. Hazard. Mater. 2010, 175, 970. doi: 10.1016/j.jhazmat. 2009.10.105

(32) Sheng, G. D.; Shao, D. D.; Ren, X. M.; Wang, X. Q.; Li, J. X.; Chen, Y. X.; Wang, X. K. J. Hazard. Mater. 2010, 178, 505. doi: 10.1016/j.jhazmat.2010.01.110

(33) Pan, J. M.; Zou, X. H.; Wang, X.; Guan, W.; Yan, Y. S.; Han, J. A. Chem. Eng. J. 2010, 162, 910. doi: 10.1016/j.cej.2010.06. 039

(34) Liu, Y. J. Chem. Eng. Data 2009, 54, 1981. doi: 10.1021/ je800661q

(35) Liu, Q. S.; Zheng, T.; Wang, P.; Jiang, J. P.; Li, N. Chem. Eng. J. 2010, 157, 348. doi: 10.1016/j.cej.2009.11.013

(36) Hamdaoui, O.; Naffrechoux, E. J. Hazard. Mater. 2007, 147, 401. doi: 10.1016/j.jhazmat.2007.01.023 